Original Article

\title{
Habitual Physical Exercise and Osteoarthritis of the Knee in Female
}

${ }^{*}$ Emran $\mathrm{M}^{1}$, Hasan $\mathrm{MI}^{2}$, Ahmed $\mathrm{SM}^{3}$, Shahin $\mathrm{MA}^{4}$,Newaz F${ }^{5}$, Ahmed B ${ }^{6}$, Alam MM${ }^{7}$, Rahamn $\mathrm{HH}^{8}$

\begin{abstract}
The study aimed to evaluate the association of recreational (habitual) physical activities with the osteoarthritis (OA) of the knee in the female. The case-control study was carried out at the Bangabandhu Sheikh Mujib Medical University (BSMMU), Dhaka in the year 2016 and 2017. The total participants were 174 female selected purposively with the age range of $40-70$ years, among them 87 were the cases with $O A$ of the knee, and the same number of the same age group were included as the control without $O A$ of the knee. A structured interviewer-administered questionnaire was used to collect data. High level of physical activities (20 or more miles per week) was associated with $O A$ of the knee, whereas moderate level of physical activities (10-20 miles/per week) and low level of physical activities ( $<10$ miles/per week) had no significant association with the $O A$ of the knee. This study reveled the relationship of the physical activity and $O A$ of the knee. Continue physical activity according to the public
\end{abstract}

1. *Dr. Mohammed Emran, Assistant Professor, Department of Physical Medicine and Rehabilitation, Khwaja Yunus Ali Medical College and Hospital, Sirajganj, Bangladesh. Mobile: 01717497497, E-mail: emran.pmr@gmail.com

2. Dr. Md. Israt Hasan, Medical Officer, Department of Physical Medicine and Rehabilitation, Kurmitola General Hospital, Dhaka.

3. Dr. Syed Mozaffar Ahmed, Professor, Department of Physical Medicine and Rehabilitation, BSMMU, Dhaka.

4. Dr. Md. Abu Shahin, Associate Professor, Department of Rheumatology, BSMMU, Dhaka.

5. Dr. Fatema Newaz, Consultant of Physical Medicine and Rehabilitation, LABAID, Mymensingh.

6. Dr. Badrunnessa Ahmed, Associate Professor, Department of Physical Medicine and Rehabilitation, BSMMU, Dhaka.

7. Dr. Md. Mahfuzul Alam, Medical Officer, Department of Physical Medicine and Rehabilitation, Kurmitola General Hospital, Dhaka.

8. Dr. Hasan Habibur Rahman, Medical Officer, Department of Physical Medicine and Rehabilitation, Kurmitola General Hospital, Dhaka. ${ }^{*}$ For correspondence health guideline, may eliminate this such physical problem for the general health promotion and particularly to prevent the $O A$ of the knee.

Keywords: Osteoarthritis, physical activity, exercise, risk factor

\section{INTRODUCTION}

The biomechanical influence of anthropometric changes and habitual physical activity levels are important linked contributory factors which may play a role in the prevalence and symptomatology of osteoarthritis in aging women. ${ }^{1}$

The beneficial health effects of physical activity are well known, include increased longevity and decreased incidence of cardiovascular disease, diabetes, obesity, and hypertension. ${ }^{2-3}$ One of the potentially hazardous effects of physical activity is osteoarthritis. ${ }^{4}$ Female gender, age, obesity, previous joint injury, occupational activities are known risk factors for both hip and knee osteoarthritis. ${ }^{5}$

There is an increased risk of developing hip and knee OA with specific strenuous exercise and long term physical activity were detected among general population, here wear and tear theory of joint degeneration related to repetitive joint loading. ${ }^{6-8}$

Other studies report that moderate and strenuous physical activities including recreational running do not significantly increase the risk of OA. ${ }^{9-10}$

While many kinds of physical activity require repetitive joint use that may cause cartilage attrition, physical activity can help in preventing OA in different ways like strengthening the muscular support around joints and thereby reduces the risk of joint injury, improve and maintains joint mobility by preventing the joints from 'freezing up' and physical activity helps to avoid obesity, a risk factor for some forms of OA. Finally, mature cartilage cells receive nourishment only from the diffusion of substances through the cartilage matrix from the joint fluid as because cartilage has no blood vessels or nerves, and physical activity enhances this process. ${ }^{11}$

A widely promoted way to improve and maintain health is leisure-time physical activity. The potential effect of physical activity on OAis important to understand. 
Previous studies on the impact of physical activity on the knee joint have reported conflicting findings. Moreover, few studies have been carried out on this fact in Bangladesh.

Therefore, this study was aimed to explore theinteraction between physical activities with the osteoarthritisof the knee inthe female.

\section{MATERIALSAND METHODS}

Thecase-control study was done on $174 \mathrm{female}$ participants who were selected purposively with the age range of 40-70 years at BSMMU in the year 2016 and 2017. They were divided into the two groups where 87 patients withosteoarthritis of the knee as the caseand 87 without osteoarthritis of the knee werein the control group. A structured interviewer-administered questionnaire, enquiring about demographic data and details of the exercise pattern was used to collect the data. The Institutional Review Board of the BSMMU reviewed and approved all the procedures of this study. The physical, psycho-social and legal risk were minimum. The participants were well informed to give written consent before enrollment and they had the right to participate or refuse or even withdraw from the study at any point in time. The privacyof the data information was maintained strictly.

The chosen physical activitieswere walking, running, jogging here because they were the most common activity for this population and they were assessed by self-reported regular exercise patterns. Among those who reported any regular exercise, three levels of activity were defined. The high level- physical activity more than 20 miles per week; moderate level - physical activity between 10 and 20 miles per week andlowlevel - physical activity up to 10 miles per week.

TheStatistical Package for Social Sciences version 23.0 for Windows was used to analyze all relevant information. The quantitative observations were in frequencies and percentages. Thecategorical variables were analyzed by the Chi-Squared test, showed with cross tabulation. The considered statistically significantp-value was $<0.05$.

\section{RESULTS}

The mean age was 57 years.

Table-I: shows regular physical activity of the respondents. Among the 87 patients, 55 were doing a high level of physical activities, the value was 41 in the control group and the $\mathrm{P}$ value was significant $(<0.05)$. The low level of physical activities and a moderate level of physical activities were not statistically significant $(\mathrm{p}>0.05)$ between the two groups.

Table I: Regular physical activity of the respondents

\begin{tabular}{|l|c|c|c|c|}
\hline $\begin{array}{l}\text { Regular physical } \\
\text { activity (miles } \\
\text { /per week) }\end{array}$ & $\begin{array}{c}\text { Case } \\
(\mathrm{n}=87)\end{array}$ & $\begin{array}{c}\text { Control } \\
(\mathrm{n}=87)\end{array}$ & $\begin{array}{c}\text { OR (95\% } \\
\text { CI })\end{array}$ & $\begin{array}{c}\mathrm{P} \\
\text { value }\end{array}$ \\
\hline Low $(<10)$ & 7 & 14 & $\begin{array}{c}2.19 \\
(0.77-6.40)\end{array}$ & $0.103^{\mathrm{ns}}$ \\
\hline Moderate $(10-20)$ & 25 & 32 & $\begin{array}{c}0.69 \\
(0.35-1.37)\end{array}$ & $0.258^{\mathrm{ns}}$ \\
\hline High $(>20)$ & 55 & 41 & $\begin{array}{c}1.93 \\
(1.01-3.70)\end{array}$ & $0.032^{\mathrm{s}}$ \\
\hline
\end{tabular}

$\mathrm{s}=$ significant, $\mathrm{ns}=$ not significant

\section{DISCUSSION}

This study gives an idea about the relation of physical activity to the OA of the knee in female aged 40 to 70 and above in this region.

This study revealed a positive association between the high level of physical activity and the OA of the knee where the mean age was 57 years. However, the OA of the knee was not significantly associated with the physical activities in low level and physical activities in a moderate level.

It proves the Marti et al study where they have explained that the exercise of high-intensity over a long period of time may be responsible for the premature OA. ${ }^{12}$

Another study favors this studywhere it is observed that the weight-bearing sports like running, jogging, etc. can increase the risk of radiographic OA of the knees in women. ${ }^{13}$

Some studies reported conflicting findingsinvestigating the impact of physical activity on the knee joint. Few of them declaredthe physical activity as a risk factor for the OA of the knee. ${ }^{6,13-14}$

Among the walkers and runners the female gender is contributing along with the other risk factors for the OA of the Knee. ${ }^{15}$

The high level of physical activity was showed significant for the OA of the knee in a study and so did ours. This is may be happening due to cartilage degeneration by transmitting repetitive impact and torsional loads to the large weight-bearing joints such as the hip and knee. ${ }^{16}$ 
In this study, the moderate level of physical activity and low level of physical activity were not associated with the osteoarthritis of the knee and that was seen in other studies. They all explored, the physical activity in moderate level did not increase the risk of OA without significant joint injury. ${ }^{1,7,17-23}$

It wasdescribed in a study thatthe recreational exercises did not increase the risk of the radiographic OA of the knee in middle-aged and elderly persons. ${ }^{24}$

Other studies observed that the degenerative changes of the knee joint might not be caused by the physical activity moreovercould even be protected by it. ${ }^{8,24-26}$

The similarity of this study with others is the high level of physical activities have an association with the OA of the knee while it differs in the moderate level and low level of physical activities which are not associated.

The suggestion is to follow the public health guideline and continue regular physical exercise. ${ }^{27-28}$ This message will be helpful for the health promotion in general and particularly theOAof the knee can be prevented.

\section{CONCLUSIONS}

This study findings support the conclusion that a high level of physical activities has a significant association with osteoarthritis of the knee in the female. Whereas, moderate level and low level of physical activities have no effect on osteoarthritis of the knee.

\section{RECOMMENDATION}

To avoid the OA of the knee, low level ( $<10$ miles/per week) and a moderate level (10-20 miles/per week) of habitual/regular physical exercise like walking, jogging or running is recommended.

\section{Acknowledgment}

The authors are grateful to the BSMMU, Dhaka for providing a grant to conduct this study. Authors also sincerely thank theparticipants of the study.

Conflict of interest: The authors declared no conflict of interest.

\section{REFERENCES}

1. White JA, Wright V, Hudson AM. Relationships between Habitual Physical Activity and Osteoarthrosis in Ageing Women. Public Health 1993; 107: 459-470.
2. Pate R, Pratt M, Blair S, Haskell W, Macera C, Bouchard C, et al. Physical activity and public health: a recommendation from the Centers for Disease Control and Prevention and the American College of Sports Medicine. JAMA 1995; 273(5):402-7.

3. Blair S, Kohl H, Barlow C, Paffenbarger R, Gibbons $\mathrm{L}$, Macera C. Changes in physical fitness and all-cause mortality: a prospective study of healthy and unhealthy men. JAMA 1995; 273(14):1093-8.

4. Pate R, Macera C. Risks of exercising: Musculoskeletal injuries. In: Bouchard C, Shepard R, Stephens T, editors. Physical activity, fitness and health: international proceedings and consensus statement. Champaign, IL: Human Kinetics Publishers, 1994: 1008-18.

5. Felson D, Zhang Y. An update on the epidemiology of knee and hip osteoarthritis with a view to prevention. Arthritis Rheum 1998; 41(8): 1343-55.

6. Cheng Y, Macera C, Davis D, Ainsworth B, Troped P, Blair S. Physical activity and self-reported, physician-diagnosed osteoarthritis: Is physical activity a risk factor?. J Clin Epidemiol 2000;53:315-22.

7. Cooper C, Snow S, McAlindon T, Kellingray S, Stuart B, Coggon D, et al. Risk factors for the incidence and progression of radiographic knee osteoarthritis. Arthritis Rheum 2000;43(5):995-1000.

8. Hart D, Doyle D, Spector T. Incidence and risk factors for radiographic knee osteoarthritis in middle-aged women: the Chingford Study. Arthritis Rheum 1999;42(1):17-24.

9. Hannan M, Felson D, Anderson J, Naimark A. Habitual physical activity is not associated with knee osteoarthritis: the Framingham Study. J Rheumatol 1993;20(4):704-9.

10. Lane N, Oehlert J, Bloch D, Fries J. The relationship of running to osteoarthritis of the knee and hip and bone mineral density of the lumbar spine: a 9-year longitudinal study. J Rheumatol 1998;25(2):334-41.

11. Hall AC, Urban JPG, Gehl KA. The effects of hydrostatic pressure on matrix synthesis in articular cartilage. J Orthop Res 1991;9:1-10.

12. Marti B, Tschopp KA, Jucker A, Howald H. Is excessive running predictive of degenerative joint disease?. Controlled study of former elite athletes. 
British Medical Journal, 1989;299: 91-93.

13. Spector TD, Harris PA, Hart DJ, Cicuttini FM, Nandra D, Etherington J, Wolman R, Doyle DV. Risk of osteoarthritis associated with long-term weight-bearing sports: a radiologic survey of the hips and knees in female ex-athletes and population controls. Arthritis Rheum 1996;39:988-95.

14. Szoeke C, Dennerstein L, Guthrie J, Clark M, Cicuttini F. The relationship between prospectively assessed body weight and physical activity and prevalence of radiological knee osteoarthritis in postmenopausal women. J Rheumatol 2006;33:1835-1840.

15. Gabriel SE. Update on the epidemiology of the rheumatic diseases. Curr Opin Rheumatol 1996; 8:96-100.

16. Buckwalter J, Lane N. Athletics and osteoarthritis. Am J Sports Med 1997;25(6):873-81.

17. Hootman JM, Macera CA, Helmick CG, Blair SN. Influence of physical activity-related joint stress on the risk of self-reported hip/knee osteoarthritis: a new method to quantify physical activity. Prev Med 2003;36:636-644.

18. Sandmark H, Vingard E. Sports and risk for severe osteoarthritis of the knee. Scand J Med Sci Sports 1999;9(5):279-84.

19. Panush RS, Schmidt C, Caldwell JR, Edwards NL, Longley $S$, Yonker R, et al. Is running associated with degenerative joint disease?. JAMA 1986; 255: $1152-4$

20. Cooper C, McAlindon T, Snow S, Vines K, Young P, Kirwan J, et al. Mechanical and constitutional risk factors for symptomatic knee osteoarthritis: differences between medial tibiofemoral and patellofemoral disease. J Rheumatol 1994;21:301-13.
21. Bagge E, Bjelle A, Eden S, Svanborg A. Factors associated with radiographic osteoarthritis: results from the population study 70-year old people in Goteborg. J Rheumatol 1991;18(8):1218-22.

22. Lau E, Cooper C, Lam D, Chan V, Tsang K, Sham A. Factors associated with osteoarthritis of the hip and knee in Hong Kong Chinese: obesity, joint injury and occupational activities. Am J Epidemiol 2000;152(9): 855-62.

23. Manninen P, Riihimaki H, Heliovaara M, Suomalainen O. Physical exercise and risk of severe knee osteoarthritis requiring arthroplasty. J Rheumatol 2001;40:432-7.

24. Felson D, Niu J, Clancy M, Sack B, Aliabadi P, Zhang $Y$ : Effect of recreational physical activities on the development of knee osteoarthritis in older adults of different weights: The Framingham Study. Arthritis Rheum 2007; 57:6-12.

25. Rogers LQ, Macera CA, Hootman JM, Ainsworth BE, Blair SN. The association between joint stress from physical activity and self-reported osteoarthritis: an analysis of the Cooper Clinic data. Osteoarthritis and Cartilage 2002; 10: 617-622.

26. Urquhart DM, Soufan C, Teichtahl AJ, Wluka AE, Hanna F, Cicuttini FM. Factors that may mediate the relationship between physical activity and the risk for developing knee osteoarthritis. Arthritis Research and Therapy. 2008;10:203.

27. U.S. Department of Health and Human Services. Healthy People 2010. Washington, DC: U.S. Department of Health and Human Services 2000.

28. U.S. Department of Health and Human Services. Physical Activity and Health: A Report of the Surgeon General. Atlanta, GA: U.S. Department of Health and Human Services, Centers for Disease Control and Prevention, National Center for Chronic Disease Prevention and Health Promotion 1996. 